\title{
Dynamic Capabilities for Accreditation: Evidence in the Healthcare Sector
}

\author{
Mariana Monteiro Meira ${ }^{1}$ \\ André Gustavo Carvalho Machado ${ }^{2}$ \\ Glauco Ricardo Simões Gomes ${ }^{3}$ \\ Centro Universitário de João Pessoa, João Pessoa, PB, Brazil ${ }^{1}$ \\ Universidade Federal da Paraíba, João Pessoa, PB, Brazil ${ }^{2}$ \\ Universidade Federal de Minas Gerais, Belo Horizonte, MG, Brazil ${ }^{3}$
}

Received 11 October 2018. This paper was with the authors for two revisions. Accepted 16 February 2019. First published online 26 March 2019.

Breno Augusto Diniz Pereira was the associate editor for this article.

Editorial assistant: Luciane Kato Kiwara

Editor-in-chief: Carlo Gabriel Porto Bellini 


\begin{abstract}
The objective of this paper is to analyze the development of dynamic capabilities in the process of hospital accreditation, using case study methodology. Data were collected through semistructured interviews, observation and document analysis and analyzed through content analysis techniques. We found that deliberate learning and relationships were the principal sources for capability creation, and that they were renewed and recombined along the way. Periods of convergence punctuated by strategic reorientation allowed us to conclude that the changes adhered to the punctuated equilibrium model. The outcomes of this study advance the findings documented in the literature about the construction of a formative path of dynamic capabilities, understanding the duality of operational and dynamic capabilities, and comprehending the mechanisms by which capabilities are developed.
\end{abstract}

Key words: dynamic capabilities; capability sources; lifecycle. 


\section{Introduction}

Worldwide, the healthcare macro sector is said to dynamize an economy due to its capacity for producing goods and services, creating new knowledge, and absorbing technology (Minayo, 2010). However, factors such as high costs, insufficient quality and limited access to healthcare have brought commotion, unrest and frustration to all those involved, whether patients or workers, putting the sector under pressure to provide good-quality and reliable services (Porter \& Teisberg, 2006). One response to this situation is hospital accreditation, which is a periodical and voluntary assessment of institutional resources based on continued education set to guarantee the quality of assistance according to pre-established standards (Manzo, Brito, \& Corrêa, 2012). Many organizations disseminate requisites for hospital accreditation around the world, including the Brazilian National Accreditation Organization ([ONA] Organização Nacional de Acreditação, in Portuguese), which determines a sequential three-level accreditation, with requirements regarding an institution's structure, processes and outcomes. Therefore, this requires that the organization make a set of changes to meet specific demands throughout the transition between the several levels.

In turn, such changes imply altering the way things are done in the present, destroying knowledge that is no longer worth applying, and creating and - consequently - recreating and extending that which will be used in the future. Thus, the accreditation process may be understood as an outcome of changes that generate and transform resources and capabilities. Such argumentative logic adheres to the concept of dynamic capability proposed by Helfat et al. (2007, p.1), which we adopt in this paper: "the capacity of an organization to purposefully create, extend, or modify its resource base".

Although, historically, academic research investigating dynamic capabilities have covered themes such as strategy and innovation, in recent years, studies have been conducted under different perspectives, thus broadening the scope of dynamic capabilities and strengthening its explanatory power for comprehending organizational reality. In this sense, in consonance with AlbortMorant, Leal-Rodríguez, Fernández-Rodríguez and Ariza-Montes (2018), dynamic capabilities have been used to explain, among other issues: technology transfers (Fernandes \& Machado, 2019); the creation of capacities for engineering projects (Freitas \& Salerno, 2018); the development of wine tourism (Lavandoski, Silva, Vargas-Sánchez, \& Pinto, 2017) and supply chain collaboration (Mandal, 2017).

However, there is some complexity to the study of dynamic capabilities, especially due to the lack of consensus about a tautological definition (Tondolo \& Bitencourt, 2014), due to the factors that influence their development and implications within organizations (Barreto, 2010; Cardoso \& Kato, 2015; Gonzalés, Sáez, \& Castro, 2009; Guerra, Tondolo, \& Camargo, 2016; Laaksonen $\&$ Peltoniemi, 2018), in addition to their difficult identification and classification (BarralesMolina, Bustinza, \& Gutiérrez-Gutiérrez, 2013; Helfat \& Winter, 2011). However, analyzing the process of hospital accreditation as a backdraft for the development of dynamic capabilities can mitigate such complexity, for the requisites for certification require documenting the evolution and administration of the organization, reflecting about what does and what does not contribute 
to the development of the organization, as well as formalizing and disseminating all activities (Vargas, Albuquerque, Erdman, \& Ramos, 2007).

This approach is believed to counter criticism regarding methodological and theoretical aspects of dynamic capability studies (Barreto, 2010; Eriksson, 2013; Laaksonen \& Peltoniemi, 2018), especially those associated with: (a) the necessity of investigating the relations, boundary conditions and contingency of the analyzed capabilities (whether dynamic and/or operational); (b) a more careful choice of the sample and greater consistency in terms of the level of analysis throughout the investigation; (c) the use of longitudinal data, and, finally; (d) the analysis of outcomes and learning opportunities deriving from the development of dynamic capabilities.

With this in mind, this study's research question was designed as follows: how does the development of dynamic capabilities support the process of hospital accreditation? To answer this question, the central objective of this paper is to analyze the development of dynamic capabilities in the process of hospital accreditation. More specifically, in this study, we sought to identify dynamic capability sources; investigate the lifecycle stages of the principal dynamic capabilities at each accreditation level; and describe the organizational changes resulting from the accreditation process. Thus, we conducted a qualitative research, using case study methodology in a hospital that reached the third level of hospital accreditation (the top level of accreditation as set by ONA).

The outcomes of this paper advance the understanding about the capability lifecycles (proposed by Helfat \& Peteraf, 2003), as they explain and exemplify how the principal capabilities of hospital accreditation are created and evolve along their different ways. The empirical evidence also complements the findings of other research about constructing a formative path of dynamic capabilities and their impacts on organizational performance (Gelhard \& von Delft, 2016; Gelhard, von Delft, \& Gudergan, 2016; Mikalef \& Pateli, 2017); the duality between operational and dynamic capabilities (Helfat \& Winter, 2011); and understanding the learning and relationship mechanisms through which capabilities are developed (Meirelles \& Camargo, 2014).

Following this introduction, the next section provides a brief background on organizational changes and dynamic capabilities. After that, we outline our methodological procedures, and discuss our results. Finally, we present the outcomes for this research.

\section{Organizational Changes and Dynamic Capabilities}

The hospital accreditation process implies changes in several areas of an organization, such as: administration and management, medical staff organization, system reviews, organization of infirmary, facilities and security, as well as defining and planning the role of the hospital (Juul et al., 2005). In addition, it is necessary to define new performance indicators, transform the medical practice, set new procedures, replace functions and assess the very relation of the hospital with the setting (Greenfield \& Braithwait, 2008; Pomeyet, Contandriopoulos, François, \& Bertrand, 2004). Therefore, the theme change assumes a prominent role in the process of accreditation and may be understood in three different dimensions: content (what will be 
changed), process (how it will be changed) and context (why change is necessary) (Pettigrew, 1987).

From a procedural standpoint, there are four principal theoretical frameworks of change: Lifecycle, Teleology, Dialectics and Evolution Theories (Van De Ven \& Poole, 1995). This paper adopts an Evolutionary framework, which considers change to be a recurrent progression in three phases within the organization: variation (random change); selection (selecting the best change to adjust to the setting); and retention (maintaining the selection to counter variations) (Nelson \& Winter, 1982).

Nevertheless, the way change takes place within an evolutionary framework is not yet at a consensus and has generated three principal types of evolutionary theories: ecological, adaptative and transformational. In an effort to relate them, Tushman and Romanelli (1985) proposed the punctuated equilibrium model, which understands organizational progress by means of convergent periods punctuated by reorientations that influence the next period of convergence.

To said authors, the causes that lead to crossing from one period to another result from two forces: inconsistency in the activities due to a misalignment with strategic orientation, which causes low performance; profound changes in social, legal, competitive and technological conditions that make the former strategic orientation obsolete. These two forces lead to a period of reorientation, which implies fundamental changes in the following domains: strategy, structure, power distributions, control systems and beliefs/values. Therefore, the changes made for accreditation are believed to follow the behavior predicted by the punctuated equilibrium model (Assumption 1).

The transition between periods requires creating different capabilities due to the need to forge new consistency, structure and processes (Tushman, Newman, \& Romanelli, 1986). Change is allowed, then, by the generated capabilities (Wu, Qile, Yanqing, \& O'Regan, 2012). In turn, capabilities evolve over time to adjust to settings characterized by constant transformations, behaving in different ways throughout the periods.

In this perspective, the dynamic capabilities (DC) approach is believed to have the potential to elucidate how the capabilities necessary for hospital accreditation are developed, since they are skills used to create, integrate, build and reconfigure resources that enable detecting and exploring opportunities and responding, in due time, to the changes imposed by the environment (Adner \& Helfat, 2003; Andreeva \& Chaika, 2006; Teece, 2007; Teece, Pisano, \& Shuen, 1997). Thus, during the accreditation process, capabilities are believed to behave dynamically (Assumption 2)

Due to such characteristics, the DC are categorized as superior or higher-order capabilities (Winter, 2003). They differ, therefore, from operational, ordinary or zero-level capabilities (Winter, 2003), because, while the former capabilities involve committing to strategic changes, the latter capabilities reflect an ability to perform the basic functional activities of the firm (Collis, 1994). 
On the other hand, although some authors (Laaksonen \& Peltoniemi, 2018) call attention to the importance of empirical research that consider such differences, others (Helfat \& Winter, 2011) highlight the difficulties of such an objective, including the fact that some capabilities encompass both purposes; that is, they are both dynamic and operational at the same time. In addition, Helfat et al. (2007) understand that capabilities may develop in settings with different dynamics, for whatever reasons that imply reconfiguring the resources of the organization.

In turn, capabilities arise from an organized group under a leadership whose objective is to accomplish a task (Helfat \& Peteraf, 2003; Winter, 2003). In line with such argument, Schoemaker, Heaton and Teece (2018) underscore how important it is that upper management get involved in the development of (and support for) dynamic capabilities in the organization. To Nonaka, Hirose and Takeda (2016), upper management has the mission to empower the tactical and operational levels with adequate resources to develop the dynamic capabilities necessary to the organization.

Although there is no consensus about capability sources, in consonance with Helfat et al. (2007), Romme, Zollo and Berends (2010) and Schilke, Hu and Helfat (2018), they are believed to generate from the following sources: Deliberate Learning, Relationships and Acquisitions. Examples of each may be found in recent works: Li and Liu (2014), Bingham, Heimeriks, Schijven and Gates (2015), Wilden and Gudergan (2015) and Wang, Hung Li and Ding (2018).

Zollo and Winter (2002) especially value Deliberate Learning and its respective mechanisms: Experience Accumulation, Knowledge Articulation and Knowledge Codification. In this sense, dynamic capabilities come from the interrelation between the activity of the organizational and experiential knowledge, that which is articulated and that which is codified (Floriani, Borini, \& Fleury, 2009) and may be identified by means of investments, such as in training, formally written procedures, manuals and discussion forums that foster the dissemination and transformation of knowledge into routines (Romme, Zollo, \& Berends, 2010). Nembhard and Tucker $(2011,2016)$ discuss how deliberate learning may support performance increases and guarantee accountability in health organizations.

Besides Deliberate Learning, another source of capability involves Relationships (alliances, outsourcing, patents, licenses), by means of transfer, recombination or creation of a specific knowledge created which could not (or would be more expensive to) be achieved in isolation (Agarwal, Anand, Bercovitz, \& Croson, 2012; Dyer \& Singh, 1998). Relationships, however, are rather complex and difficult to maintain for many reasons, such as (but not only): insufficient absorptive capabilities, lack of credibility, motivation, causal ambiguity, and difficult relationships between involved parties (Szulanski, 1996).

Capron (2013) underscores the scenarios in which there is an elevated risk of dissemination of confidential strategic information, or, simply, the impossibility of acquiring a resource through relationship sources or deliberate learning. There emerges the need for more control, making acquisition the last resource. Although it is unusual in the hospital sector, acquisitions have grown with the rise in competitiveness, especially with hospitals in stable markets that wish to 
increase their share, transforming small hospitals into extensions of their capabilities for acute health cases (Minich-Pourshadi, 2010). In this context, it is understood that, during the accreditation process, dynamic capabilities are created through deliberate learning, relationships and/or acquisitions (Assumption 3).

Despite the substantial number of studies on dynamic capabilities, little has been discussed about their behavior and lifecycle, that is, the set of possible trajectories that characterize their evolution through specific stages (Keil, McGrath, \& Tukiainen, 2009). Although Helfat and Peteraf (2003), in a pioneering way, suggested a few stages (founding, development and maturity), the authors call the attention to the fact that empirical research needs to be conducted to better clarify the behavior of capabilities in each proposed stage. Therefore, even one decade after the initial proposition of said authors, the evolution of capabilities during their lifecycles remains only partly understood (Floreddu \& Vitari, 2013). However, recent research sheds light on the issue and minimize the distance between conceptual developments and empirical studies.

Mukherjee (2012), for example, identifies the capabilities acquired by emerging firms in globalization processes in each of the capability lifecycle phases. Similarly, Sambharya and Lee (2014) present empirical results that the development of dynamic capabilities in multinational firms positively influence their process of entering foreign markets through diversification.

Based on a study conducted with around 100 firms in Eastern Europe, Rungi (2015) discusses that the quality of most business-related dynamic capabilities tend to decrease as they enter the decline stage. However, this does not occur in the context of project-related capabilities, since their quality tends to improve in this stage of the lifecycle. More recently, Bernardo, Galina and Pádua (2017) produced a framework in which the dynamic capability lifecycle of Business Process Management is analyzed to incorporate elements of the external setting. All this considered, we understand that, throughout the accreditation process, dynamic capabilities behave according to the Lifecycle stages proposed by Helfat and Peteraf (2003) (Assumption 4).

Considering all that has been discussed in this section, Table 1 synthesizes the definitions of the fundamental constructs that will be developed throughout this article, the four theoretical assumptions and the authors of the principal works we relied on. 
Table 1

Theoretical reference synthesis

\begin{tabular}{|c|c|c|c|}
\hline Constructs & Definitions & Assumptions & Main authors \\
\hline $\begin{array}{l}\text { Organizational } \\
\text { change }\end{array}$ & $\begin{array}{l}\text { "Any change, whether planned or } \\
\text { unplanned, in the organization, due } \\
\text { to internal and/or external factors, } \\
\text { which has some impact on the } \\
\text { results and/or people's relationships } \\
\text { at work" (Bruno-Faria, 2003, p. 128, } \\
\text { our translation). }\end{array}$ & $\begin{array}{l}\text { (1) Changes made for } \\
\text { accreditation follow the } \\
\text { behavior predicted by the } \\
\text { punctuated equilibrium } \\
\text { model. }\end{array}$ & $\begin{array}{l}\text { (Nelson \& Winter, 1982) } \\
\text { (Tushman \& Romanelli, } \\
\text { 1985) }\end{array}$ \\
\hline $\begin{array}{l}\text { Dynamic } \\
\text { capabilities }\end{array}$ & $\begin{array}{l}\text { "The capacity of one organization to } \\
\text { purposefully create, extend and } \\
\text { modify its resource base" (Helfat et } \\
\text { al., 2007, p. 1). }\end{array}$ & $\begin{array}{l}\text { (2) During the accreditation } \\
\text { process, capabilities behave } \\
\text { in a dynamic way. }\end{array}$ & $\begin{array}{l}\text { (Helfat et al., 2007) } \\
\text { (Helfat \& Winter, 2011) } \\
\text { (Winter, 2003) } \\
\text { (Teece, Pisano, \& Shuen, } \\
\text { 1997) }\end{array}$ \\
\hline $\begin{array}{l}\text { Dynamic capability } \\
\text { sources }\end{array}$ & $\begin{array}{l}\text { Elements through which it is } \\
\text { possible to create and develop } \\
\text { dynamic capabilities. }\end{array}$ & $\begin{array}{l}\text { (3) Throughout the } \\
\text { accreditation process, } \\
\text { dynamic capabilities are } \\
\text { created through deliberate } \\
\text { learning, relationships } \\
\text { and/or acquisitions. }\end{array}$ & $\begin{array}{l}\text { (Zollo \& Winter, 2002) } \\
\text { (Romme et al., 2010) } \\
\text { (Dyer \& Singh, 1998) }\end{array}$ \\
\hline $\begin{array}{l}\text { Capability } \\
\text { lifecycles }\end{array}$ & $\begin{array}{l}\text { Set of possible paths that } \\
\text { characterize the evolution of } \\
\text { capabilities through specific stages } \\
\text { (Keil et al., 2009). }\end{array}$ & $\begin{array}{l}\text { (4) Throughout the } \\
\text { accreditation process, } \\
\text { dynamic capabilities behave } \\
\text { according to the Lifecycle } \\
\text { stages proposed by Helfat } \\
\text { and Peteraf (2003). }\end{array}$ & (Helfat \& Peteraf, 2003) \\
\hline
\end{tabular}

Finally, Figure 1 illustrates the relationships between the constructs and their respective assumptions.

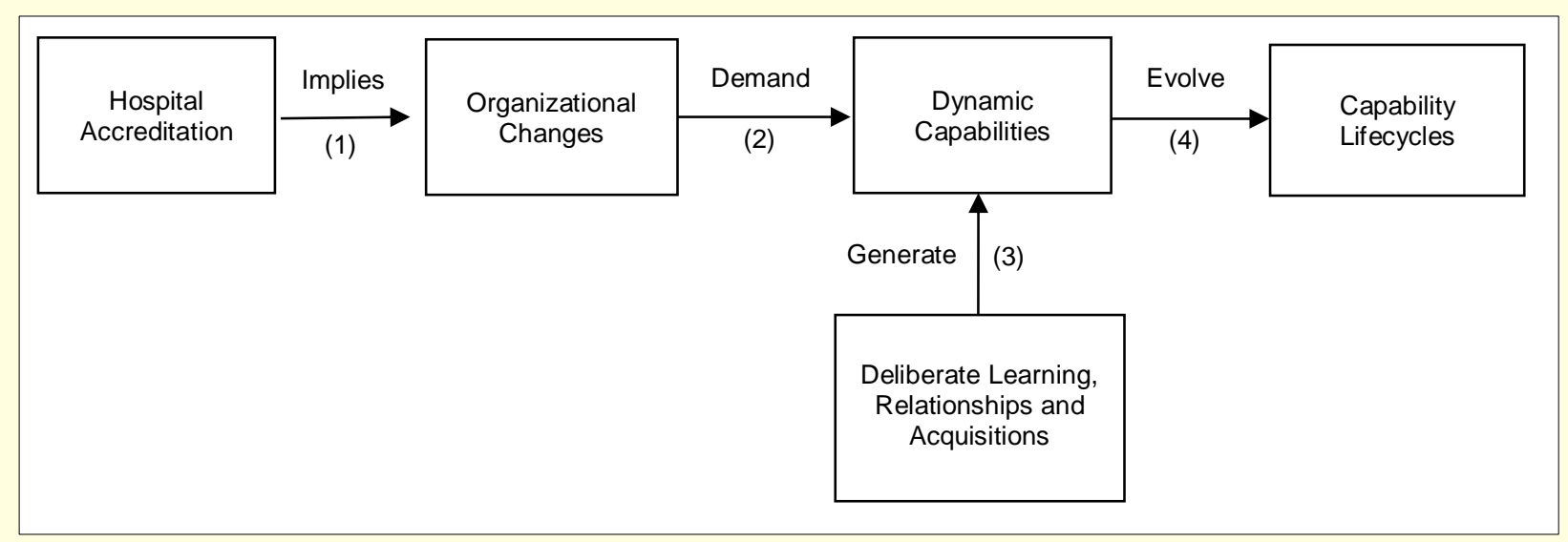

Figure 1. Theoretical relationships among constructs 


\section{Methodological Procedures}

The research strategy used in this study was a case study, which has been the choice of many works on dynamic capabilities (Agarwal \& Selen, 2009; Capron, 2013; Helfat \& Peteraf, 2009; Kale, Dyer, \& Singh, 2002; Michailova \& Zhan, 2015; Nembhard \& Tucker, 2011; Wu et al., 2012). Three criteria were adopted for picking the case: (a) to be located in Brazil's northeast region (to enable data collection); (b) to have reached ONA's third and final level of hospital accreditation; and (c) responding positively, and in due time, to the invitation to participate in this research. At first, four hospitals were pre-selected for meeting the first two requisites. After initial contact, one of the hospitals accepted to participate in the study, provided that it was identified by a fictitious name: Hospital Zeta.

Hospital Zeta (HZ) is located in Recife, capital city of the Brazilian state of Pernambuco, and has 1,500 staff and 500 outsourced collaborators. The hospital's specialties are: emergency, clinical medicine, general surgery, cardiology, vascular surgery, neurology and neuroscience, traumatology, oncology, hemodynamics, burns, urology, gynecology and obstetrics, and pediatrics.

The procedures for collecting the data required approximately 45 days, and the principal technique used was the semi-structured interview. We had a script of 22 questions in three sections. The first section, with four questions, aimed to identify the principal capability involved in each level of accreditation. We first explained the meaning of capabilities to the respondents. Next, we asked questions about the capabilities necessary for and those put to use throughout the long process of accreditation; which of them were minimally standardized and were part of the hospital's routine; why such capabilities were selected; and which professionals became involved in their creation.

The second section comprised 10 questions and was set to identify the behavior of the capabilities over time, based on the capability lifecycle model proposed by Helfat and Peteraf (2003) and their respective sources, namely, Helfat et al. (2007) and Romme et al. (2010). The third section had eight questions and aimed to assess the behavior of organizational changes on a set of domains suggested by Tushman and Rommaneli (1985): strategy, structure, power distributions, beliefs/values and control systems. All the interviews were recorded and were late transcribed.

In order to highlight path dependence (Rungi, 2015; Teece et al., 1997; Vasconcellos, Garrido, Vieira, \& Schneider, 2015) and the need for a multilevel and multidimensional approach to the process of dynamic capability development (Barreto, 2010), the interviewees were those who participated in the whole process of accreditation throughout the three levels in different positions and areas within the organizations. They were: Quality Coordinator, Quality Analyst, Quality Assistant, Clinical Audit Nurse and the Storeroom Manager. The number of interviewees was also justified by the theoretical saturation of the data.

Complementarily, we used direct observation and document analysis techniques. The former technique was applied in visitations to sectors of the surveyed hospital, such as patient reception, 
administrative areas, intensive care units (ICUs), beds, hospital garbage disposal places, and the pharmacy. In such places we verified the interaction of the staff, their routine, as well as communication elements such as signs, warnings, and procedures. All observations were recorded in a field journal.

Documents were collected at the same time interviews were conducted. Documents were prompted or shown voluntarily as a way to register the conducted activities. We checked manuals, training records, process maps, minutes, organograms, indicator reports, photos, footage, records for knowledge management programs, protocols, alliance contracts, purchasing and licensing contracts, as well as communication with clients.

We analyzed data in four stages, based on content analysis techniques (Bardin, 1977) and procedures suggested by Merriam (1998). At first, the collected data were read to check if the answers we had were enough. In the second step, the transcripts were sent to the interviewees for them to evaluate if the content was accurate. In the third step, the data were grouped according to thematic categories created in this step after rereading the transcripts, based on the perception of which themes might represent common topics, to facilitate the comprehension and relation of the collected data, namely: organizational changes, dynamic capability sources, and capability lifecycles. Finally, in the fourth step, we conducted the analysis by thematic categories, by comparing the collected data with the pertinent literature.

\section{Results Presentation and Discussion}

This section is divided into two subsections. The first subsection analyzes the organizational changes resulting from the accreditation process according to five different domains. The second subsection presents a diagnosis of how the capabilities were created and developed over time, including the learning mechanisms, the dynamic capability sources and lifecycle.

\section{Organizational change}

In consonance with Tushman and Rommaneli (1985), accreditation brought about changes in strategy, structure, control systems, power distributions and values, as shown in Table 2. 
Table 2

\section{Changes found in $\mathrm{HZ}$}

\begin{tabular}{ll}
\hline Change domains & Characteristics \\
\hline Strategy & Strategy was created through strategic planning. \\
\hline Structure & $\begin{array}{l}\text { Organizational: positions were eliminated and created, the organogram was changed. } \\
\text { Physical: ICU and number of beds were expanded; equipment was bought. }\end{array}$ \\
\hline Power distributions & $\begin{array}{l}\text { Empowerment, new leaders were instituted for each sector, follow-up at each sector } \\
\text { became more specialized. }\end{array}$ \\
\hline Control systems & $\begin{array}{l}\text { Indicators were created based on accreditation requirements and an indicator follow- } \\
\text { up system. } \\
\text { Communication patterns were reshaped, SOPs were created, protocols were } \\
\text { structured, performance assessment was created. }\end{array}$ \\
\hline Values & Institutional values were created, conduct policies were created and disseminated. \\
\hline
\end{tabular}

From a strategic perspective, change occurred because, up until then, the culture of planning and evaluating the long-term consequences of actions was inexistent. At first, transformations included developing the statements of mission, vision and values, under the logic of strategic planning, and adopting strategic management tools. This was especially important for accreditation, for it reflected a change in behavior and strategic orientation of the hospital, which was in search of a more focused and uniform work methodology, as can be noticed in the statement of interviewee 3 .

"We did not even know what strategic planning was. It was all very new, the fact of planning the following year surprised us. Then, we thought about our strategic objectives. At first, we were a team, each one had their own objective. Now, we are a team under one single mission. We have to be 'interdisciplinary', for one person's activity is sure connected to those of others."

Both the organizational and physical structure were modified. Based on the observations we conducted, we noticed that the physical structure changes were in the expansion of the diagnostic center, procedure computerization, purchasing top-class equipment for the surgical center, increasing the material variety, expansion of the surgical center, and digital imaging exams.

The organizational changes involved adjustments in the work methodology and the organogram, in an attempt to make the process controls more objective. Examples of changes in the organogram and, consequently, in the power distribution, were the eliminated positions, such as those of nursing manager per floor, which was taken over by one macro manager for every three floors. Supervisors for each position were replaced by macro managers per area. The ICUs were down to a single general manager. According to the Quality Coordinator, such measures were meant to empower the sectors to conduct their tasks, because a more focused management would increase the decision-making speed.

The document and records analysis showed that positions were created for some activities to be followed up from up-closer and more autonomously. For example, rather than just one general direction, three direction offices were created: one medical direction, with coordinators for 
emergency, surgical center, nursing; administrative direction, in charge of back-up, hotel sector, food, maintenance, laundry, telephone and orderlies; and, financial direction, in charge of billing, storeroom, purchases, and pre-admission of patients.

The distribution of materials that come into the hospital was also modified. Before the certification process, all material was kept in one single sector, under the responsibility of the pharmaceutical area. Today, there is a central pharmacy and other peripheral units, and a storeroom that manages the entire chain of receivables, such as equipment, food, cleaning products, and surgical material.

In addition, in conformity with Pettigrew (1987), changes were also made in the control system; such changes were proven by statements and documents. In this area, we point out the modifications in the communication patterns and performance assessment. The communication patterns, previously informal, were documented and standardized, and several types of periodical meetings were created (root cause meetings, strategic meetings and audit meetings, for example).

The changes in the systems that influence performance occurred by adopting indicators and process management, which was not done by the organization before. The performance assessment was introduced in the organization and comprised individual and sector analysis. In the former assessment, each member of the staff is evaluated for their performance, and a strategy is designed for them to reach their professional goals. The sector performance analysis relies on indicators and comparison of conducted actions to those designed in the process mapping, indicating the points of the activity that were not done as planned.

In addition, values went through changes, which is considered one of the most notable and most difficult to carry out. Such values are displayed in the form of a statement and are part of the conduct policy, a document that contains the expected behavior in the hospital. In their statements, the interviewees considered that, had the values not changed, accreditation could not have been maintained, as can be noticed in the statement given by interviewee 1 .

"It is very hard to get people to design processes, to follow them, and make them think in the long run, on interdependent teams with a single objective, changing the way we do things. (...) So, when we sought accreditation, we needed to define our values for them to support these peoples' actions. Then, we eventually defined [our values] at meetings to set up our strategic planning."

From the observations we conducted and the findings about the transformations in the different organization domains, there is strong evidence that the changes followed the logic of the Punctuated Equilibrium Model, which is a behavior that follows the evolutionary change predicted by Tushman and Romanelli (1985). This understanding corroborates the first assumption of our study, as discussed below.

The Punctuated Equilibrium predicts two moments: Convergence and Reorientation, although they may overlap. The moment of Convergence was identified as that prior to getting certified, for it is the moment for analyzing the current status to prepare for the change through planning 
the control systems, as well as the communication patterns and improvements to be implemented.

Reorientation was understood as a set of changes in previously mentioned strategy, power relations, structure, control systems and values. The moment of returning to Convergence, after Reorientation, was due to the fact that a search for a new level of accreditation implies some refinement typical of Convergence and more radical changes typical of Reorientation, making different moments of punctuated equilibrium take place, concomitantly, in different processes or functional areas of the hospital: while one process is done and must be refined, another is required at another moment, or affected by some new technology and must be modified.

Such empirical evidence contributes to confirm the theoretical arguments of Gupta, Smith and Shalley (2006), as, in a single domain, changes follow the logics of punctuated equilibrium, whereas in multiples domains of one organization, accreditation involves dealing simultaneously - with periods of evolutionary and revolutionary changes.

This means that managers will have to develop skills to explore, in a balanced way, conflicting learning approaches (March, 1991), which require different capabilities, structures, cultures, processes and strategies (He \& Wong, 2004). Although some studies have focused on analyzing the relations between such different approaches (He \& Wong, 2004; Morgan \& Berthon, 2008), the results of our study contribute to advancing knowledge, since they help explain how to reach them.

The transformations deriving from the changes made, throughout the organizational evolution, require developing dynamic capabilities; this will be the object of the next section.

\section{Developing dynamic capabilities}

The principal dynamic capabilities mentioned by the interviewees, in each level of accreditation, were: Contract Management (Level 1), Protocol Management (Level 2), and Outcome Management (Level 3). The dynamic capability Contract Management refers to the ability to negotiate and keep service contracts to guarantee the success of the acquisition or contract. Thus, this capability involves a firm's relationship routines with clients, suppliers, staff and outsourced workers.

Protocol Management was defined as a capability relative to the routines of meeting the health standards issued by Health Societies, which must be followed - by law - for being scientifically validated practices. The Outcome Management capability was defined as a set of monitoring routines for all of the hospital's standards, and the articulation between protocol management and control management.

In the three capabilities, we found Deliberate Learning mechanisms as proposed by Zollo and Winter (2002): Experience Accumulation, Knowledge Articulation, and Knowledge Codification, which were also considered by Romme et al. (2010) and Nembhard and Tucker 
(2011) in their respective studies. For the Contract Management capability, Experience Accumulation and Knowledge Articulation were more intensely used, because it was necessary to rethink, as a whole, how certain procedures were conducted, considering both the successful and unsuccessful previous experiences to define the new routines. By analyzing some contracts, and based on the interviewees' statements, and in consonance with Winter (2003), we found that the elements that compose the routines are standardized and institutionalized, making up the Knowledge Codification mechanism.

The Protocol Management capability requires discussion meetings and sharing experiences (knowledge articulation), based on the experience accumulated by the members involved with creating protocols. For example, the heart surgery protocol involves the tools supplier, nurses and doctors, who must hold meetings to build the process of introducing such protocol into the routine. After creating the protocol, knowledge must be documented in writing in order to be standardized; that is, knowledge must be codified.

As to the Outcome Management capability, the Experience Accumulation mechanism helped the learning process, for the staff had already taken in the knowledge about accreditation and were sensitized to the need to alter routines towards reaching the last accreditation level. Therefore, they created the new capability and, then, Knowledge Codification took place through flow charts and training for the knowledge to be absorbed. After codification, it was time for Knowledge Articulation by promoting the new capability in meetings, training and forums.

To create the three capabilities, the Relational capability source was used, to some extent, as proposed by Dyer and Singh (1998). Of the four Relational mechanisms (alliances, outsourcing, patents and licenses), only two of them were evidenced: outsourcing and alliances. Laboratory, cleaning and hospital garbage disposal were outsourced, which helped the hospital achieve the routines more rapidly. The alliance, in turn, occurred by means of partnerships with external suppliers, internal sectors and clients, defined and formally recorded in documents that outline the participation of each party in such relationships, as proposed by Kale, Dyer and Singh (2002).

Although Szulanski (1996) predicts difficulties in relationship management, such as causal ambiguity, lack of credibility and motivation, such hardships were not evidenced in this study's case. Such result seems to be founded on mechanisms adopted to mitigate the potential difficulties, such as the structured practice (designed processes, pre-defined documents), clear expected outcomes and customized relationship. Table 3 synthesizes the findings about the use of capability sources. 
Table 3

\section{Dynamic capability sources for $\mathrm{HZ}$}

\begin{tabular}{|c|c|c|c|}
\hline \multirow[b]{2}{*}{ Source } & \multicolumn{3}{|l|}{ Dynamic capabilities } \\
\hline & Contract management & Protocol management & Outcome management \\
\hline \multirow[t]{6}{*}{ Deliberate learning } & $\begin{array}{l}\text { a) Knowledge codification: } \\
\text { manuals, tools and written }\end{array}$ & \multirow{6}{*}{$\begin{array}{l}\text { a) Knowledge } \\
\text { codification: Meetings to } \\
\text { design and discuss the } \\
\text { protocols; } \\
\text { b) Experience } \\
\text { accumulation: Meetings } \\
\text { to share experiences; } \\
\text { c) Knowledge } \\
\text { articulation: Meetings to } \\
\text { decide on capability } \\
\text { creation. }\end{array}$} & \multirow{6}{*}{$\begin{array}{l}\text { a) Knowledge codification: flow } \\
\text { charts and training; } \\
\text { b) Experience accumulation: it } \\
\text { used the experience of prior } \\
\text { capabilities; } \\
\text { c) Knowledge articulation: } \\
\text { Meetings, training and forums. }\end{array}$} \\
\hline & \multirow{5}{*}{$\begin{array}{l}\text { procedures; } \\
\text { b) Experience } \\
\text { accumulation: Group } \\
\text { meetings about } \\
\text { conducting the } \\
\text { procedures, } \\
\text { considering prior } \\
\text { experience; } \\
\text { c) Knowledge articulation: } \\
\text { Meetings and } \\
\text { dissemination of manuals. }\end{array}$} & & \\
\hline & & & \\
\hline & & & \\
\hline & & & \\
\hline & & & \\
\hline Relationship & $\begin{array}{l}\text { Outsourcing laboratory, } \\
\text { garbage and cleaning } \\
\text { management; Alliance } \\
\text { with external suppliers and } \\
\text { internal sectors. }\end{array}$ & $\begin{array}{l}\text { Alliance with clients and } \\
\text { suppliers. }\end{array}$ & $\begin{array}{l}\text { Previous outsourcing and } \\
\text { alliances. }\end{array}$ \\
\hline
\end{tabular}

The empirical results about the components that involve the dynamic capability sources present, according to Meirelles and Camargo (2014), important theoretical implications, as they explain how and why some deliberate learning mechanisms and relationship mechanisms were used to generate dynamic capabilities.

However, against the third assumption of this study, although acquisitions can reduce the risks when business partners share strategic knowledge (Capron, 2013) and contribute to develop multiple dynamic capabilities (Bingham, Heimeriks, Schijven, \& Gates, 2015), this source was not evidenced in our study.

Under the perspective of the capabilities behavior over time, both Contract Management and Protocol Management were found to have gone through the three stages of the Capability Lifecycle proposed by Helfat and Peteraf (2003). In the first stage (founding), a team had been assigned to develop the Contract Management capability, to assure that the entire hospital was included. Likewise, for the Protocol Management capability, a group was formed to transform the medical practices into processes, and then improve and disseminate them.

In the second stage (capability development), the group gained experience and chose the best alternative to enhance their capabilities. In this sense, they chose to review all processes, periodically, through learning by doing. The interviewees alleged that they identified that the capability had reached full development, since it was acknowledged by the certifying organs. Thus, it was time to think about the path the capability should take to reach the third stage: maturity. From the collected evidence, we noticed that, in this stage, capabilities were renewed through process map reviews and flow chart changes. 
The search for the third level of accreditation, which focuses on processes of strategy and continuous improvement, required that the Contract Management and Protocol Management capabilities, which were being renewed, start to recombine to form the Outcome Management capability. In this sense, while in the first two levels the capabilities were created individually, with no common processes, the third level required that both capabilities have processes that are more and more integrated through deliberate learning and relationships, as we can infer from the following statement of interviewee 1 .

"This simultaneous relation that two sets of routines were interconnected did not exist before; there were two different sets of routines because we were learning by doing each one. After we made it, it was time to get it all together and make it work. Because this is what we have to know how to do to [achieve] the third level: not one or another, but, rather, both of them together".

Creating this new capability involved incorporating routines, documentation and discussing new themes. This capability was created by the same sectors and teams that had created the previous capabilities; however, this time, they worked together. Figure 2, below, is meant to synthesize the findings about the Capability Lifecycle of HZ, as proposed by Helfat and Peteraf (2003).

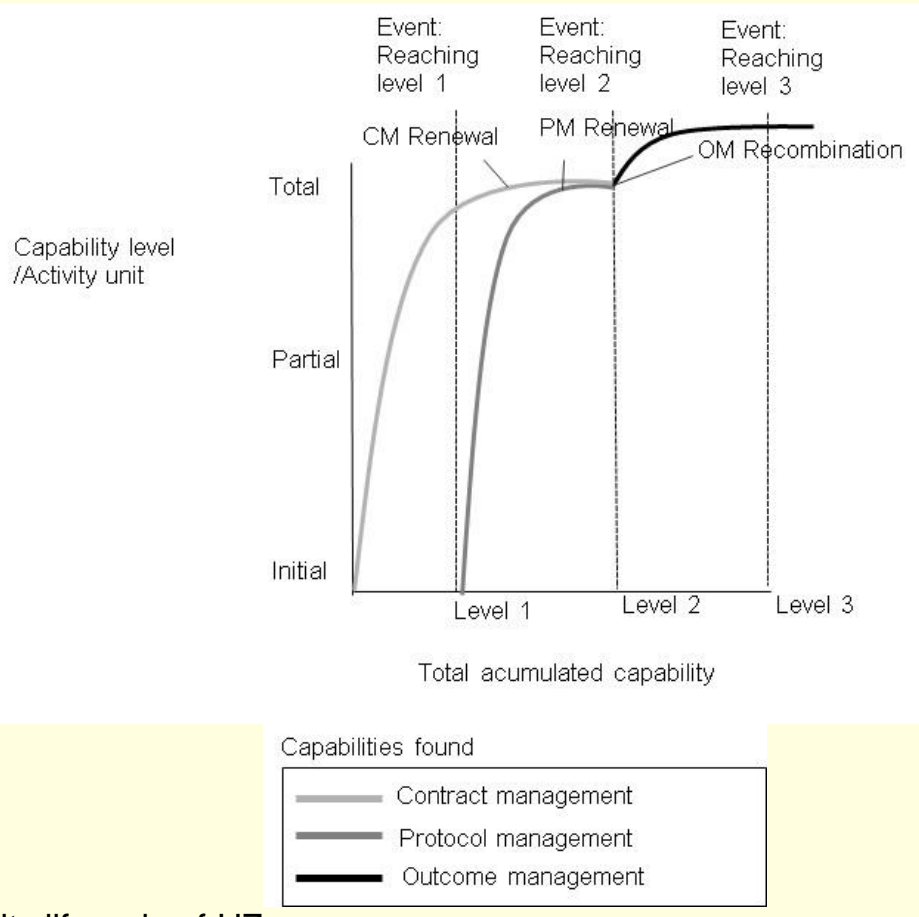

Figure 2. Capability lifecycle of $\mathrm{HZ}$

In Figure 2 the curve does not have an S shape, which means there is no change in the level of use of the capability. Still, we see the onset of the Contract Management capability (CM) before reaching level 1, its renewal after the certification and its continual use on level 2 . We also see that Protocol Management (PM) appears after level 1, and, once such level is reached, the capability went through renewal and was still used up to the moment in which it was merged with Contract Management, after level 2, to recombine such capabilities to form the Outcome Management (OM) dynamic capability, towards reaching certification level 3. Such capability 
recombination to form another one, as well as its graphic representation, starting at a point of the cycle different from the origin, confirms the assertions of Helfat et al. (2007) that they are not static; that is, the routines and resources go through transformations over time.

Evidence as to how capabilities evolved throughout the accreditation process confirms the fourth assumption of our study. The empirical results, analyzed longitudinally, contribute to advance the research on dynamic capabilities, according to Vasconcellos, Garrido, Vieira and Schneider (2015), for they help explain how organizational characteristics and decisions made throughout a firm's history, through path dependencies for hospital accreditation, influence the development of capabilities. At the same time, our findings help fill some theoretical gaps, especially about the "need for studies on organizational processes involving the development and use of such capabilities” (Takahashi, Bulgacov, \& Giacomini, 2017, p.376).

Besides describing the mechanisms used to develop the dynamic capabilities on each one of the accreditation stages and their evolution over the lifecycle phases, we also found that the capability purposes changed over time, which corroborates the assertions of Helfat and Winter (2011) about the duality of the operational and dynamic capabilities.

In this perspective, the Contract Management capability (accreditation level 1) has initial characteristics that adhere to the higher-order capability, also named dynamic capability (Winter, 2003). However, as this very capability approaches the maturity stage, and, concomitantly, progresses in the process of accreditation, we noticed a dual behavior (also near the multilevel activity mentioned by Barreto, 2010), as discussed next.

When applied to the routines of patient assistance, such as purchasing prostheses and equipment for imaging exams, for example, a capability is dynamic. The reason for this is that the routines that need to meet some requisites of hospital accreditation, due to the dynamism of the hospital sector (Agwunobi \& Osborne, 2016) and to the environmental changes that occurred in the country (Herrmann, Sangalli, \& Teece, 2017), require transformations of resources over time to include changes of behavior, processes, attitudes and documentation.

However, in addition to meeting the requisites for accreditation and being dynamic, such capability is also applied to routines that support the daily work of a hospital. Thus, when it comes to the basic operation routines of hospitals, such as those involved in supplying food to the restaurant and storeroom material, rather than create and substantially modify resources, it was responsible, mainly, for incremental changes, which may be better understood according to Winter (2003) as ordinary or operational capabilities.

Capabilities associated with accreditation levels 2 and 3, unlike those of level 1, presented a single purpose throughout time. That is, since they were created to allow the effective modification and reconfiguration of existing resources, potentializing, among other things, the creation of new capabilities, Protocol Management and Outcome Management capabilities are solely dynamic capabilities.

Evidence is against the second assumption of this study, which asseverates that during the process of accreditation capabilities would behave in a dynamic way. Unlike our initial perception, it was 
possible to notice - confirming Helfat and Winter (2011) - that capabilities may behave both dynamically and operationally.

Understanding that there is a hierarchy among capabilities, whereby dynamic capabilities are ranked higher, is not recent (Collis, 1994; Winter, 2003; Zollo \& Winter, 2002). However, comprehending the characteristics and relationships between capabilities of different hierarchical levels, as well as understanding the conditions on which such capabilities complement themselves, deriving from the empirical findings of this study, contribute to deepen the knowledge about the theme, according to Schilke et al. (2018).

Table 4, below, synthesizes the results of empirical evidence relative to the principal constructs analyzed.

Table 4

\section{Empirical evidence synthesis}

\begin{tabular}{lll}
\hline Constructs & Assumptions & Empirical evidence \\
\hline $\begin{array}{l}\text { Organizational } \\
\text { change }\end{array}$ & $\begin{array}{l}\text { (1) Changes made for accreditation } \\
\text { follow the behavior predicted by the } \\
\text { punctuated equilibrium model. }\end{array}$ & $\begin{array}{l}\text { Accreditation went through changes in different domains } \\
\text { (strategy, structure, control systems, power distribution, } \\
\text { values) and followed the Punctuated Equilibrium logics, with } \\
\text { periods of convergence and reorientation. }\end{array}$
\end{tabular}

\begin{tabular}{lll}
\hline $\begin{array}{l}\text { Dynamic } \\
\text { capabilities }\end{array}$ & $\begin{array}{l}\text { (2) During the accreditation process, } \\
\text { capabilities behave in a dynamic way }\end{array}$ & $\begin{array}{l}\text { Unlike our initial understanding, we found that the Contract } \\
\text { Management capability had a dual behavior, at times having } \\
\text { dynamic capability characteristics and at other times having } \\
\text { operational capability characteristics. }\end{array}$ \\
\hline $\begin{array}{l}\text { Dynamic } \\
\text { capability sources }\end{array}$ & $\begin{array}{l}\text { (3) Throughout the accreditation } \\
\text { process, dynamic capabilities are } \\
\text { created through deliberate learning, } \\
\text { relationships and/or acquisitions. }\end{array}$ & $\begin{array}{l}\text { Although capabilities were generated through deliberate } \\
\text { learning mechanisms (knowledge codification, experience } \\
\text { accumulation, knowledge articulation) and relationships } \\
\text { (alliance and outsourcing), we did not find sources of } \\
\text { capabilities originating from acquisitions. }\end{array}$ \\
\hline $\begin{array}{l}\text { Capability } \\
\text { lifecycles }\end{array}$ & $\begin{array}{l}\text { (4) Throughout the accreditation } \\
\text { process, dynamic capabilities behave } \\
\text { according to the Lifecycle stages } \\
\text { proposed by Helfat and Peteraf } \\
\text { (2003). }\end{array}$ & $\begin{array}{l}\text { In consonance with the theoretical assumption, we found } \\
\text { that the behavior - over time - of the three dynamic } \\
\text { capabilities adheres to the lifecycle proposed by Helfat and } \\
\text { Peteraf (2003). }\end{array}$ \\
\hline
\end{tabular}

Evidence, therefore, confirms our first theoretical assumption. Our second and third theoretical assumptions were not confirmed entirely, since such capability did not only behave in a dynamic way, but also in an operational way, and acquisitions were not found to be sources for the generation of capabilities. Finally, our fourth assumption was confirmed. Such evidence suggest the need for development of future studies, as will be outlined in the following section. 


\section{Conclusions}

Our results confirmed that the fundamental capabilities for accreditation were, in fact, dynamic, requiring constant revision, expansion and modification of resources. Identifying, developing and transforming capabilities, over time, to meet internal needs and the external demands of the hospital sector - deriving, for example, from greater competition levels and changes in the political scenario and legislation, in line with Agwunobi and Osborne (2016) and Herrmann, Sangalli and Teece (2017) - requires dealing with different sources of learning and relationship.

In the first case, the mechanisms of Experience Accumulation, Knowledge Articulation and Codification were explored to develop the capabilities on every level of accreditation. When it comes to mechanisms of the Relational source, only outsourcing and alliances were adopted in levels and capabilities different from accreditation.

Another important outcome of our work concerns the duality of the purposes of the capabilities evidenced in their relations with the accreditation stages and lifecycle phases. The capability associated with level 1 presented, at first, dynamic capability characteristics. As it reached more advanced phases of the lifecycle, this very capability at times behaved as an operational capability while at other times as a dynamic capability. Level 2 and 3 capabilities, in turn, starting with their creation, behaved as dynamic capabilities.

The way the organizational change occurred, from the perspective of the evolutionary theory of Nelson and Winter (1982), led to the conclusion that it adhered to the Punctuated Equilibrium model proposed by Tushman and Rommaneli (1985). In this sense, we spotted periods of convergence pervaded by periods of reorientation, characterized by transformations that occurred in different domains (strategy, structure, power relations, control systems, values).

From the theoretical viewpoint, the outcomes of this study contribute to bridge the gaps relative to the lack of empirical evidence about dynamic capabilities (Laaksonen \& Peltoniemi, 2018; Tondolo \& Bitencourt, 2014), their lifecycle (Helfat \& Peteraf, 2003), learning mechanisms (Meirelles \& Camargo, 2014) and how they develop over time (Arend \& Bromiley, 2009; Takahashi et al., 2017) and their relations with path dependencies (Vasconcellos et al., 2015) and operational capabilities (Schilke, Hu, \& Helfat, 2018). In addition, we could spot the sources involved in their creation, how and why they were used, as well as the development options that were chosen and the paths followed in the moment of maturity. In the managerial perspective, the evidence from this study may guide hospital managers as to the path to be taken for accreditation, as we identified the main capabilities developed and the reasons for their use.

Refining the initial understanding that generated the assumptions of our study implies an agenda of new research to be developed to answer the following questions: what managerial skills are needed to simultaneously handle periods of incremental and revolutionary changes? Are there differences in the behavior and characteristics of the learning and relationship mechanisms between dynamic and operational capabilities? What are the principal challenges teams have to face during the lifecycle stages of capabilities? Considering that only alliances and outsourcing 
were used as sources of relationship to generate dynamic capabilities, how do patents and licenses contribute to that very purpose?

Finally, since the case we analyzed did not use acquisitions to create dynamic capabilities, we suggest that further research study some hospital that is part of a group that has taken over other units, to understand the development of dynamic capabilities for hospital accreditation also from this perspective. Based on such scenario, it would be possible to shed light on the role of deliberate learning among organizations of one single group, as well as obtain new insights on more recent issues such as the influence of the business model (Teece, 2018) in the process of developing dynamic capabilities.

\section{Contributions}

1st author: research question and main objectives; theoretical basis; methodological procedures; results presentation and discussion; conclusions.

2nd author: research question and main objectives; results presentation and discussion; conclusions.

3rd author: results presentation and discussion; conclusions.

\section{References}

Adner, R., \& Helfat, C. E. (2003). Corporate effects and dynamic managerial capabilities. Strategic Management Journal, 24(10), 1011-1025. https://doi.org/10.1002/smj.331

Agarwal, R., Anand, J., Bercovitz, J., \& Croson, J. (2012). Spillovers across organizational architectures: the role of prior resource allocation and communication in post-acquisition coordination outcomes. Strategic Management Journal, 33(6), 710-733. https://doi.org/10.1002/smj.1965

Agarwal, R., \& Selen, W. (2009). Dynamic capability building in service value networks for achieving service innovation. Decision Sciences, 40(3), 431-475. https://doi.org/10.1111/j.1540-5915.2009.00236.x

Agwunobi, A., \& Osborne, P. (2016). Dynamic capabilities and healthcare: A framework for enhancing the competitive advantage of hospitals. California Management Review, 58(4), 141-161. https://doi.org/10.1525/cmr.2016.58.4.141

Albort-Morant, G., Leal-Rodríguez, A. L., Fernández-Rodríguez, V., \& Ariza-Montes, A. (2018). Assessing the origins, evolution and prospects of the literature on dynamic capabilities: A bibliometric analysis. European Research on Management and Business Economics, 24(1), 42-52. https://doi.org/10.1016/j.iedeen.2017.06.004

Andreeva, T., \& Chaika, V. (2006). Dynamic capabilities: What they need to be dynamic? St. Petersburg, Russia: St. Petersburg State University.

Arend, R. J., \& Bromiley, P. (2009). Assessing the dynamic capabilities view: Spare change, everyone? Strategic Organization, 7(1), 75-90. https://doi.org/10.1177/1476127008100132

Bernardo, R., Galina, S. V. R., \& Pádua, S. I. D. (2017). The BPM lifecycle: How to incorporate a view external to the organization through dynamic capability. Business Process Management Journal, 23(1), 155-175. https://doi.org/10.1108/bpmj-12-2015-0175

Bardin, L. (1977). Análise de conteúdo. Lisboa, Portugal: Edições 70.

Barrales-Molina, V., Bustinza, O. F., \& Gutiérrez-Gutiérrez, L. J. (2013). Explaining the causes and effects of dynamic capabilities generation: A multiple-indicator multiple cause modeling approach. British Journal of Management, 24(4), 571-591. https://doi.org/10.1111/j.1467-8551.2012.00829.x 
Barreto, I. (2010). Dynamic capabilities: A review of past research and an agenda for the future. Joumal of Management, 36(1), 256-280. https://doi.org/10.1177/0149206309350776

Bingham, C. B., Heimeriks, K. H., Schijven, M., \& Gates, S. (2015). Concurrent learning: How firms develop multiple dynamic capabilities in parallel. Strategic Management Journal, 36(12), 1802-1825. https://doi.org/10.1002/smj.2347

Bruno-Faria, M. F. (2003). Criatividade, inovação e mudança organizacional. In S. M. V. Lima (Org.), Mudança organizacional: Teoria e gestão (Chap. 3, pp. 111-141). Rio de Janeiro, Brazil: FGV.

Capron, L. (2013). Cisco's corporate development portfolio: A blend of building, borrowing and buying. Strategy $\mathcal{E}$ Leadership, 41(2), 27-30. https://doi.org/10.1108/10878571311318213

Cardoso, A. L. J., \& Kato, H. T. (2015). Análise das publicações sobre capacidades dinâmicas entre 1992 e 2012 : Discussões sobre a evolução conceitual e as contribuições dos autores de maior notoriedade na área. Revista de Administração da Mackenzie, 16(3), 201-237. https://doi.org/10.1590/167869712015/administracao.v16n3p201-237

Collis, D. J. (1994). Research note: How valuable are organizational capabilities? Strategic Management Journal, 15(S1),143-152. https://doi.org/10.1002/smj.4250150910

Dyer, J. H., \& Singh, H. (1998). The relational view: Cooperative strategy and sources of interorganizational competitive advantage. Academy of Management Review, 23(4), 660-679. https://doi.org/10.5465/amr.1998.1255632

Eriksson, T. (2013). Methodological issues in dynamic capabilities research: A critical review. Baltic Journal of Management, 8(3), 306-327. https://doi.org/10.1108/bjom-jul-2011-0072

Fernandes, C. R., \& Machado, A. G. C. (2019). Technology transfer capability: Development dynamics in higher education institutions. Brazilian Business Review, 16(1), 1-15. https://doi.org/10.15728/bbr.2019.16.1.1

Floreddu, P., \& Vitari, C. (2013). Capability lifecycle and its motivating force on strategy: The case of Green IT/S Dynamic Capability. Retrieved from http://hal.grenoble-em.com/hal-00969198

Floriani, D. E., Borini, F. M., \& Fleury, M. T. L. (2009). O processo de internacionalização como elemento gerador de capacidades dinâmicas: $\mathrm{O}$ caso da WEG na Argentina e na China. Revista Brasileira de Gestão de Negócios, 11(33), 367-382. http://dx.doi.org/10.7819/rbgn.v11i33.452

Freitas, S. L. T. U., \& Salerno, M. S. (2018). Creation of dynamic capacities and their evolution through engineering projects. Revista Brasileira de Gestão de Negócios, 20(4), 495-515. http://dx.doi.org/10.7819/rbgn.v0i0.3950

Gelhard, C., \& von Delft, S. (2016). The role of organizational capabilities in achieving superior sustainability performance. Journal of Business Research, 69(10), 4632-4642. https://doi.org/10.1016/j.jbusres.2016.03.053

Gelhard, C., von Delft, S., \& Gudergan, S. P. (2016). Heterogeneity in dynamic capability configurations: Equifinality and strategic performance. Journal of Business Research, 69(11), 5272-5279. https://doi.org/10.1016/j.jbusres.2016.04.124

Gonzalés, J. C., Sáez, P. L., \& Castro, G. M. de. (2009). La influencia de lãs capacidades dinámicas sobre los resultados financieros de la empresa. Cuadernos de Estudios Empresariales,19, 105-128. Retrieved from http://revistas.ucm.es/index.php/CESE/article/view/CESE0909110105A/9246

Greenfield, D., \& Braithwaite, J. (2008). Health sector accreditation research: A systematic review. International Journal for Quality in Health Care, 20(3), 172-183. https://doi.org/10.1093/intqhc/mzn005

Guerra, R. de A., Tondolo, V. G., \& Camargo, M. E. (2016). O que (ainda) podemos aprender sobre capacidades dinâmicas? Revista Ibero-Americana de Estratégia, 15(1), 44-64. https://doi.org/10.5585/riae.v15i1.2168

Gupta, A. K., Smith, K. G., \& Shalley, C. E. (2006). The interplay between exploration and exploitation. Academy of Management Joumal, 49(4), 693-706. https://doi.org/10.5465/amj.2006.22083026

He, Z-L., \& Wong, P-K. (2004). Exploration vs. exploitation: An empirical test of the ambidexterity hypothesis. Organization Science, 15(4), 481-494. https://doi.org/10.1287/orsc.1040.0078

Helfat, C., Finkelstein, S., Mitchell, W., Peteraf, M., Singh, H., Teece, D., \& Winter, S. (2007). Dynamic capabilities: Understanding strategic change in organizations. New York, NY: Blackwell Publishing. 
Helfat, C. E., \& Peteraf, M. A. (2003). The dynamic resource based view: Capability lifecycles. Strategic Management Journal, 24(10), 997-1010. https://doi.org/10.1002/smj.332

Helfat, C. E., \& Peteraf, M. A. (2009). Understanding dynamic capabilities: Progress along a developmental path. Strategic Organization, 7(1), 91-102. https://doi.org/10.1177/1476127008100133

Helfat, C. E., \& Winter, S. G. (2011). Untangling dynamic and operational capabilities: Strategy for the (n)everchanging world. Strategic Management Journal, 32(11), 1243-1250. https://doi.org/10.1002/smj.955

Herrmann, J. D., Sangalli, L. C., \& Teece, D. J. (2017). Dynamic capabilities: Fostering an innovation-friendly environment in Brazil. Revista de Administração de Empresas, 57(3), 283-287. https://doi.org/10.1590/s0034759020170309

Juul, A., Gluud, C., Wettersley, J., Callesen, T., Jensen, G., \& Kofoed-Enevoldsen, A. (2005). The effects of a randomised multi-centre trial and international accreditation on availability and quality of clinical guidelines. International Journal of Health Care Quality Assurance, 18(4), 321-328. https://doi.org/10.1108/09526860510602587

Kale, P., Dyer, J. H., \& Singh, H. (2002). Alliance capability, stock market response and long term alliances success: The role of the alliance function. Strategic Management Journal, 23(8), 747-767. https://doi.org/10.1002/smj.248

Keil, T., McGrath, R. G., \& Tukiainen, T. (2009). Gems from the Ashes: Capability creation and transformation in internal corporate venturing. Organization Science, 20(3), 601-620. https://doi.org/10.1287/orsc.1080.0373

Laaksonen, O., \& Peltoniemi, M. (2018). The essence of dynamic capabilities and their measurement. International Journal of Management Reviews, 20(2), 184-205. https://doi.org/10.1111/ijmr.12122

Lavandoski, J., Silva, J. A., Vargas-Sánchez, A., \& Pinto, P. S. L. G. (2017). Drivers and effects of wine tourism development in wineries: The perspective of dynamic capabilities. Revista Turismo - Visão e Ação, 19(3), 458-486. https://doi.org/10.14210/rtva.v19n3.p458-486

Li, D.-Y., \& Liu, J. (2014). Dynamic capabilities, environmental dynamism, and competitive advantage: Evidence from China. Journal of Business Research, 67(1), 2793-2799. https://doi.org/10.1016/j.jbusres.2012.08.007

Mandal, D. (2017). The influence of dynamic capabilities on hospital-supplier collaboration and hospital supply chain performance. International Journal of Operations Eु Production Management, 37(5), 664-684. https://doi.org/10.1108/ijopm-05-2016-0249

March, J. G. (1991). Exploration and exploitation in organizational learning. Organization Science, 2(1), 71-87. https://doi.org/10.1287/orsc.2.1.71

Manzo, B. F., Brito, M. J. M., \& Corrêa, A. dos R. (2012). Implicações do processo de acreditação hospitalar no cotidiano de profissionais de saúde. Revista da Escola de Enfermagem da USP,46(2), 388-394. https://doi.org/10.1590/s0080-62342012000200017

Meirelles, D. S., \& Camargo, A. A. B. (2014). Capacidades dinâmicas: O que são e como identificá-las?. Revista de Administração Contemporânea, 18, 41-64. https://doi.org/10.1590/1982-7849rac20141289

Merriam, S. B. (1998). Qualitative research and case study application in education. San Francisco, CA: Jossey-Bass.

Michailova, S., \& Zhan, W. (2015). Dynamic capabilities and innovation in MNC subsidiaries. Joumal of World Business, 50(3), 576-583. https://doi.org/10.1016/j.jwb.2014.10.001

Mikalef, P., \& Pateli, A. (2017). Information technology-enabled dynamic capabilities and their indirect effect on competitive performance: Findings from PLS-SEM and fsQCA. Journal of Business Research, 70, 1-16. https://doi.org/10.1016/j.jbusres.2016.09.004

Minayo, M. C. S. (2010). O desafio do conhecimento: Pesquisa qualitativa em saúde (12a ed.). São Paulo, Brazil: HUCITEC.

Minich-Pourshadi, K. (2010, November). Hospital mergers and acquisitions: Opportunities and challenges. Brentwood, TN: Health Leaders Media Intelligence Unit.

Morgan, R. E., \& Berthon, P. (2008). Market orientation, generative learning, innovation strategy and business performance inter-relationships in bioscience firms. Joumal of Management Studies, 45(8), 1229-1353. http://dx.doi.org/10.1111/j.1467-6486.2008.00778.x 
Mukherjee, P. (2012). Evolution of dynamic capability in emerging market firms from the Indian IT industry for rapid globalization (Doctoral dissertation). Australian School of Business, University of New South Wales, Sydney, Australia.

Nelson, R. R., \& Winter, S. G. (1982). An evolutionary theory of economic change. Cambridge, MA: Harvard University Press.

Nembhard, I. M., \& Tucker, A. L. (2011). Deliberate learning to improve performance in dynamic service settings: Evidence from hospital intensive care units. Organization Science, 22(4), 907-922. https://doi.org/10.1287/orsc.1100.0570

Nembhard, I. M., \& Tucker, A. L. (2016). Applying organizational learning research to accountable care organizations. Medical Care Research and Review, 73(6), 673-684. https://doi.org/10.1177/1077558716640415

Nonaka, I., Hirose, A., \& Takeda, Y. (2016). 'Meso'-foundations of dynamic capabilities: Team-level synthesis and distributed leadership as the source of dynamic creativity. Global Strategy Journal, 6(3), 168-182. https://doi.org/10.1002/gsj.1125

Pettigrew, A. M. (1987). Context and action in the transformation of the firm. Journal of Management Studies, 24(6), 649-670. https://doi.org/10.1111/j.1467-6486.1987.tb00467.x

Pomey, M.-P., Contandriopoulos, A.-P., François, P., \& Bertrand, D. (2004). Accreditation: A tool for change in healthcare organization? International Journal of Health Care Quality Assurance, 17(3), 113-124. https://doi.org/10.1108/09526860410532757

Porter, M. E., \& Teisberg, E. O. (2006). Redefining health care: Creating value-based on results. Boston, MA: Harvard Business School Press.

Romme, A. G. L., Zollo, M., \& Berends, P. (2010). Dynamic capabilities, deliberate learning and environmental dynamism: A simulation model. Industrial and Corporate Change, 19(4), 1271-1299. https://doi.org/10.1093/icc/dtq031

Rungi, M. (2015). How lifecycle influences capabilities and their development: Empirical evidence from Estonia, a small European country. International Journal of Managing Projects in Business, 8(1), 133-153. https://doi.org/10.1108/ijmpb-06-2014-0054

Sambharya, R. B., \& Lee, J. (2014). Renewing dynamic capabilities globally: An empirical study of the world's largest MNCs. Management International Review, 54(2), 137-169. https://doi.org/10.1007/s11575-013-0199-7

Schilke, O., Hu, S., \& Helfat, C. E. (2018). Quo Vadis, dynamic capabilities? A content-analytic review of the current state of knowledge and recommendations for future research. Academy of Management Annals, 12(1), 390-439. https://doi.org/10.5465/annals.2016.0014

Schoemaker, P. J. H., Heaton, S., \& Teece, D. (2018). Innovation, dynamic capabilities, and leadership. California Management Review, 61(1), 15-42. https://doi.org/10.1177/0008125618790246

Szulanski, G. (1996). Exploring internal stickiness: Impediments to the transfer of best practice within the firm. Strategic Management Journal, 17(S2), 27-43. https://doi.org/10.1002/smj.4250171105

Takahashi, A. R. W., Bulgacov, S., \& Giacomini, M. M. (2017). Dynamic capabilities, operational capabilities (educational-marketing) and performance. Revista Brasileira de Gestão de Negócios, 19(65), 375-393. https://doi.org/10.7819/rbgn.v0i0.2831

Teece, D. J. (2007). Explicating dynamics capabilities: The nature and microfoundations of (sustainable) enterprise performance. Strategic Management Journal, 28(13), 1319-1350. https://doi.org/10.1002/smj.640

Teece, D. J. (2018). Business models and dynamic capabilities. Long Range Planning, 51(1), $40-49$. https://doi.org/10.1016/j.lrp.2017.06.007

Teece, D. J., Pisano, G., \& Schuen, A. (1997). Dynamic capabilities and strategic management. Strategic Management Journal, 18(7), 509-533. https://doi.org/10.1002/(sici)1097-0266(199708)18:7\%3C509::aid-smj882\%3E3.0.co;2-z

Tondolo, V. A. G., \& Bitencourt, C. C. (2014). Understanding dynamic capabilities from its antecedents, processes and outcomes. Brazilian Business Review, 11(5), 122-144. https://doi.org/10.15728/bbr.2014.11.5.6

Tushman, M. L., Newman, W. H., \& Romanelli, E. (1986). Convergence and upheavel: Managing the unsteady pace of organizational evolution. California Management Review, 29(1), 29-44. https://doi.org/10.2307/41165225

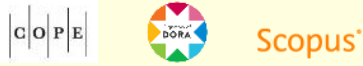


Tushman, M., \& Romanelli, E. (1985). Organizational evolution: A metamorphosis model of convergence and reorientation. Research in Organizational Behavior, 7, 171-222. Retrieved from https://www.journals.elsevier.com/research-in-organizational-behavior

Vargas, M. A., Albuquerque, G., Erdman, A., \& Ramos, F. (2007). Onde (e como) encontramos a qualidade no serviço de enfermagem hospitalar? Revista Brasileira de Enfermagem, 60(3), 339-343. http://dx.doi.org/10.1590/S0034-71672007000300018.

Vasconcellos, S. L., Garrido, I. L., Vieira, L. M., \& Schneider, L. C. (2015). Effects of path dependence on capabilities in captive global value chains. BAR - Brazilian Administration Review, 12(4), 384-402. https://doi.org/10.1590/1807-7692bar2015150041

Van De Ven, A. H. \& Poole, M. S. (1995). Explaining development and change in organizations. Academy of Management Review, 20(3), 510-540. https://doi.org/10.2307/258786

Wang, L., Hung Li, E. P., \& Ding, X. (2018). Does deliberate learning lead to dynamic capability? The role of organizational schema for Kodak, 1993-2011. Journal of Strategy and Management, 11(1), 52-80. https://doi.org/10.1108/jsma-11-2016-0083

Wilden, R., \& Gudergan, S. P. (2015). The impact of dynamic capabilities on operational marketing and technological capabilities: Investigating the role of environmental turbulence. Journal of the Academy of Marketing Science, 43(2), 181-199. https://doi.org/10.1007/s11747-014-0380-y

Winter, S. G. (2003). Understanding dynamic capabilities. Strategic Management Journal, 24(10), 991- 995. https://doi.org/10.1002/smj.318

Wu, Q., Qile, H., Yanqing, D., \& O'Regan, N. (2012). Implementing dynamic capabilities for corporate strategic change toward sustainability. Strategic Change, 21(5-6), 231-247. https://doi.org/10.1002/jsc.1906

Zollo, M., \& Winter, S. G. (2002). Deliberate learning and the evolution of dynamic capabilities. Organization Science, 13(3), 339-351. https://doi.org/10.1287/orsc.13.3.339.2780

\section{Authors}

\section{Mariana Monteiro Meira}

Centro Universitário de João Pessoa UNIPÊ

BR 230, Km 22, Água Fria, 58053-000, João Pessoa, PB, Brazil

rmonteiro.mariana@gmail.com

(iD) https://orcid.org/0000-0002-3326-1712

\section{André Gustavo Carvalho Machado}

Universidade Federal da Paraiba, Centro de Ciências Sociais Aplicadas

CCSA/UFPB, Cidade Universitária, 58043-210, João Pessoa, PB, Brazil

agcmachado@gmail.com

(iD http://orcid.org/0000-0002-0589-896X

\section{Glauco Ricardo Simões Gomes}

Universidade Federal de Minas Gerais, Centro de Pós-Graduação e Pesquisas em Administração Avenida Presidente Antônio Carlos, 6627, Pampulha, 31270-901, Belo Horizonte, MG, Brazil glaucorsg@gmail.com

(iD https://orcid.org/0000-0002-9825-9592 